07

\title{
Новые типы тандемных фотопреобразователей на основе сенсибилизированных и перовскитных солнечных элементов с центральным противоэлектродом
}

\author{
(c) М.Ф. Вильданова, А.Б. Никольская, С.С. Козлов, \\ О.И. Шевалеевский, Л.Л. Ларина
}

Институт биохимической фризики им. Н.М. Эмануэля РАН, Москва, Россия E-mail: mvildanova@sky.chph.ras.ru

Поступило в Редакцию 12 июля 2017 г.

Изготовлены тандемные солнечные элементы (ТСЭ) нового типа на основе сенсибилизированных красителем (DSC) и перовскитных (PSC) солнечных элементов с центральным противоэлектродом: DSC/DSC и DSC/PSC. Результаты исследований фотоэлектрических характеристик показали, что при освещении ТCЭ в режиме АM1.5 наиболее высокое значение эффективности преобразования солнечной энергии (14.5\%) продемонстрировала система на основе сочетания элементов DSC/DSC. При этом данные анализа работы ТСЭ на основе перовскитных элементов - DSC/PSC - указывают на высокие перспективные преимущества именно этих типов ТСЭ для получения высоких значений эффективности.

DOI: $10.21883 /$ PJTF.2018.03.45583.16967

В настоящее время мировое лидерство в производстве солнечных элементов (СЭ) принадлежит традиционным фотопреобразователям на основе кремния. При этом основные мировые научные исследования последних лет в области фотовольтаики направлены на создание эффективных и рентабельных для производства СЭ следующего поколения на базе органических и наноструктурированных систем [1-3]. Большой интерес вызывают СЭ на основе сенсибилизированных красителем мезоскопических слоев диоксида титана (dye-sensitized solar cell, DSC), впервые представленные в работах Гретцеля [4]. Максимальные значения эффективности DSC-элементов на данный момент достигли 
14\% [5] и сравнимы с эффективностью традиционных СЭ на основе микроморфного кремния [6]. Возможность дальнейшего повышения эффективности DSC ограничивается узким диапазоном оптического поглощения сенсибилизаторов. Увеличение эффективности DSC возможно за счет использования комбинации сенсибилизаторов с различными оптическими характеристиками [7,8]. Один из наиболее перспективных путей повышения эффективности заключается в применении тандемных солнечных элементов (ТCЭ), которые сочетают DSC, преобразующие различные взаимодополняющие области солнечного спектра $[9,10]$. Оптимизировать эффективность ТCЭ типа DSC/DSC можно посредством варьирования толщины активных слоев нижней и верхней ячеек, а также за счет применения различных схем электрического соединения, включая использование трехконтактной схемы с центральным противоэлектродом [10]. Значительный прогресс в поиске новых материалов для DSC был достигнут, когда в качестве сенсибилизаторов были использованы соединения на основе перовскитов, таких как $\mathrm{CH}_{3} \mathrm{NH}_{3} \mathrm{PbI}_{3}$ [11]. Благодаря высоким показателям абсорбции в видимом диапазоне и оптимальным фотоэлектрическим характеристикам перовскитных материалов солнечные элементы на их основе (perovskite solar cell, PSC) показали высокие значения эффективности, достигающие $20 \%$, и имеют значительные перспективы для использования в ТСЭ.

Целью настоящей работы является разработка и сравнительное исследование новых типов тандемных фотоэлектрических преобразователей на основе сенсибилизированных и перовскитных СЭ с центральным противоэлектродом типа DSC/DSC и DSC/PSC.

Фотоэлектроды на основе мезоскопических слоев диоксида титана для DSC- и PSC-элементов были изготовлены в соответствии с известными методиками [12,13]. В качестве подложек были использованы стекла Solaronix с проводящим покрытием FTO. При конструировании электродов на поверхности подложки путем осаждения $\mathrm{TiO}_{2}$ из $40 \mathrm{mM}$ водного раствора $\mathrm{TiCl}_{4}$ предварительно наносился барьерный слой толщиной порядка $100 \mathrm{~nm}$. Для формирования фотоэлектрода на поверхности барьерного слоя на основе наноструктурированного порошка диоксида титана (Degussa Aeroxide P25) по схеме, описанной в [14], готовилась паста, которая наносилась на подложку методом медицинской бритвы (doctor blade method) с последующим отжигом при $500^{\circ} \mathrm{C}$ в течение $30 \mathrm{~min}$. Толщина полученных таким образом мезоскопических слоев $\mathrm{TiO}_{2}$ составляла около $6 \mu \mathrm{m}$, площадь активной области $0.5 \times 0.5 \mathrm{~cm}$. 
Сенсибилизация фотоэлектродов проводилась в $0.3 \mathrm{mM}$ растворе красителя N719 в течение $24 \mathrm{~h}$. Формирование перовскитного слоя на фотоэлектродах для PSC-элементов осуществлялось согласно схеме, описанной в [15]. В качестве противоэлектродов для DSC- и PSC-элементов использовалось проводящее стекло, покрытое тонким прозрачным слоем платины $(\sim 40 \mathrm{~nm})$, осажденным из $0.01 \mathrm{M}$ раствора $\mathrm{H}_{2} \mathrm{PtCl}_{6}$. После процесса сенсибилизации фотоэлектрод и противоэлектрод были соединены между собой термоклеевой полимерной пленкой Surlyn, объем полученных ячеек был заполнен электролитом Iodolyte AN-50 (Solaronix) для DSC или изготовленным согласно [15] электролитом для PSC. Для герметизации сконструированных СЭ использовалась эпоксидная смола. На рис. 1 показана блок-схема TCЭ типа DSC/DSC и DSC/PSC, представляющего собой монолитную трехэлектродную систему, в которой рабочие фотоэлектроды соединены между собой по параллельной схеме. В качестве верхней по ходу падающего светового потока ячейки использовались СЭ типа DSC. В качестве нижней ячейки в одной серии образцов были использованы DSC-элементы, а в другой - СЭ типа PSC.

Исследование работы ТСЭ проводилось в условиях стандартного освещения AM1.5 $\left(1000 \mathrm{~W} / \mathrm{m}^{2}\right)$ с использованием солнечного имитатоpa Abet 10500 (Abet Technologies, США). Спектры действия внешней квантовой эффективности IPCE (incident photon-to-current conversion efficiency) записывались на автоматизированной системе QEX10 (PV Measurements, США) в диапазоне длин волн 350-1200 nm. Вольтамперные характеристики (BAX) СЭ были получены на универсальном анализаторе 4200-SCS (Keithley, CША). Измерения BAX проводились как для ТСЭ, так и для верхней и нижней ячеек в отдельности. КПД фотопреобразования $\eta(\%)$ рассчитывался по известной формуле

$$
\eta=\frac{J_{s c} V_{o c} F F}{P_{\text {in }}} \cdot 100 \%,
$$

где $J_{s c}-$ плотность тока короткого замыкания, $V_{o c}-$ напряжение холостого хода, $F F-$ фактор заполнения, $P_{i n}-$ интенсивность освещения.

Измерения первой серии образцов DSC/DSC показали, что в условиях AM1.5 наиболее высокое значение эффективности составило $14.5 \%$. Значения плотности тока $J_{s c}$ в ТСЭ превышают показатели индивидуальных DSC и сравнимы с суммой для верхней и нижней ячеек: $J_{s c}(\mathrm{TCЭ})=J_{s c}($ верх $)+J_{s c}$ (низ). Сравнительные диаграммы, иллюстрирующие относительные вклады плотностей тока и эффективностей

Письма в ЖТФ, 2018, том 44, вып. 3 


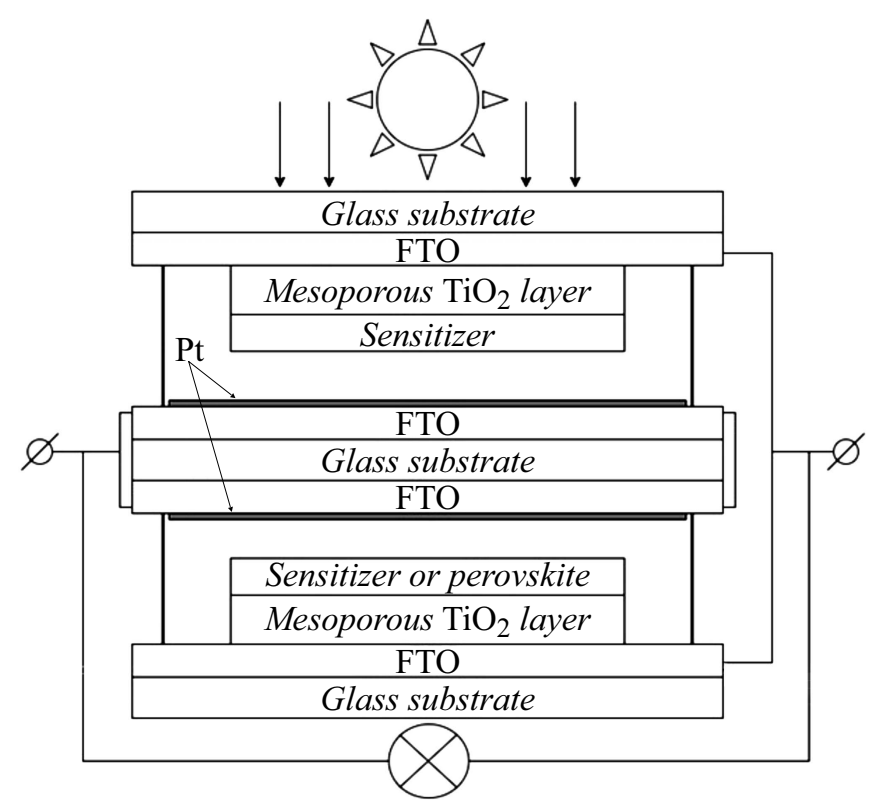

Рис. 1. Блок-схема TCЭ на основе DSC/DSC(PSC) с центральным противоэлектродом.

фотопреобразования верхней и нижней DSC-ячеек в ТCЭ, представлены на рис. $2, a$ и $b$. Среднее значение $V_{o c}$ в ТСЭ оказалось ниже, чем наблюдаемое в верхней ячейке. В то же время результирующее значение $J_{s c}$ при параллельном соединении увеличилось. Таким образом, результирующая величина эффективности ТСЭ близка к сумме его отдельных составляющих: $\eta$ (ТСЭ) $\sim \eta$ (верх $)+\eta$ (низ).

Основные фотоэлектрические характеристики серии ТСЭ типа DSC/PSC и отдельных ячеек приведены в таблице, а соответствующие BAX - на рис. 3, a. Видно, что параметры системы DSC/PSC отличаются от параметров DSC/DSC. $J_{s c}$ (TCЭ) $<J_{s c}($ верх $)+J_{s c}$ (низ), а величина $F F$ в PSC оказалась относительно низкой. При расчете эффективностей выполняется соотношение $\eta$ (ТСЭ) $\sim \eta($ верх $)<\eta($ верх $)+\eta$ (низ). Последнее обусловлено несогласованностью напряжений верхней и нижней ячеек. Таким образом, эффективность DSC/PSC-элемента лими-

Письма в ЖТФ, 2018, том 44, вып. 3 


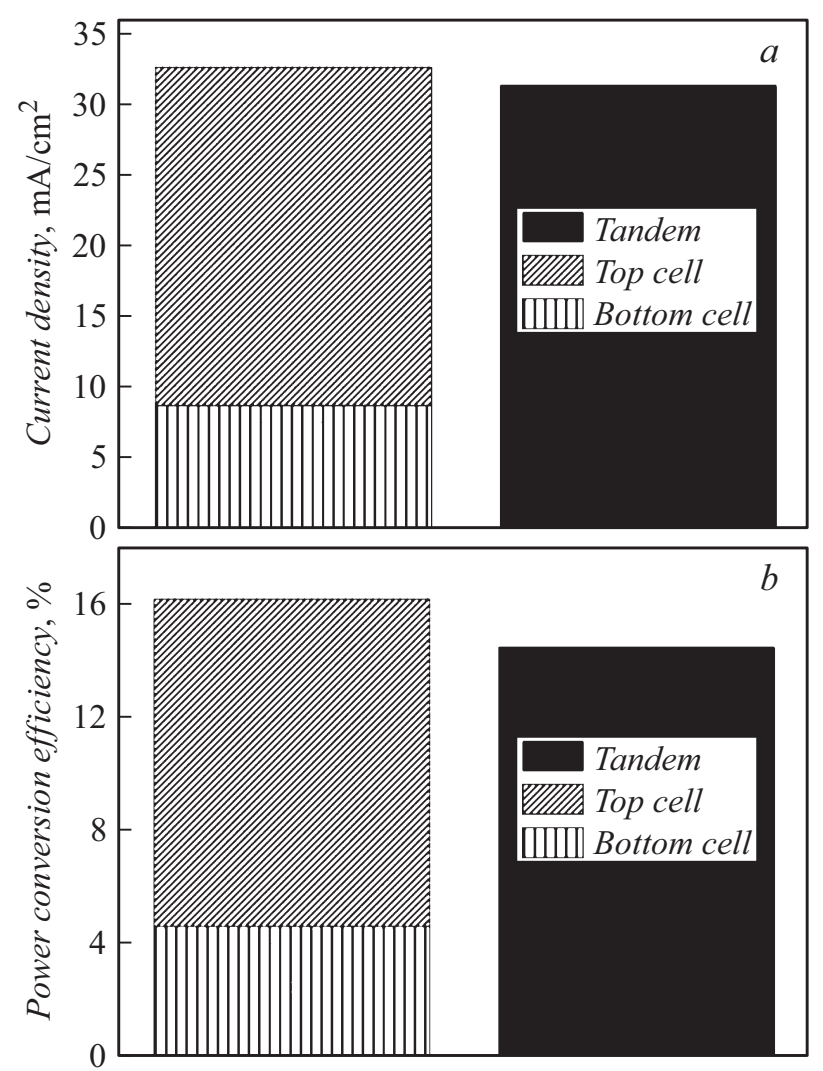

Рис. 2. Сравнительные диаграммы, показывающие соотношение плотностей генерируемого фототока $(a)$ и эффективностей фотопреобразования $(b)$ для TCЭ типа DSC/DSC и соответствующих вкладов для каждого из DSC-элементов в отдельности.

тируется низкими значениями $V_{o c}$ и $F F$ нижней ячейки PSC. Возможным путем оптимизации структуры PSC является использование в элементах твердотельных материалов, что будет способствовать стабилизации работы PSC и получению более высоких фотовольтаических параметров. Одним из наиболее существенных преимуществ перовскитов по сравнению с ранее используемыми в СЭ поглощающими слоями на

Письма в ЖТФ, 2018, том 44, вып. 3 
Фотоэлектрические характеристики верхней и нижней ячеек и ТСЭ с центральным противоэлектродом на их основе: DSC/DSC, DSC/PSC

\begin{tabular}{l|c|c|c|c}
\hline & $J_{s c}, \mathrm{~mA} / \mathrm{cm}^{2}$ & $V_{o c}, \mathrm{~V}$ & $F F$ & $\eta, \%$ \\
\cline { 2 - 5 } DSC(верх) & 23.90 & 0.820 & 0.595 & 11.6 \\
DSC(низ) & 8.69 & 0.780 & 0.680 & 4.6 \\
TCЭ DSC/DSC & 31.36 & 0.800 & 0.581 & 14.5 \\
DSC (верх) & 23.95 & 0.810 & 0.601 & 11.63 \\
PSC (низ) & 8.05 & 0.620 & 0.446 & 2.22 \\
TCЭ DSC/PSC & 28.69 & 0.760 & 0.534 & 11.56
\end{tabular}

основе органических материалов является высокое значение длины диффузии носителей заряда. Благодаря этому при конструировании PSCэлементов можно использовать перовскитные слои большой толщины, что увеличивает степень поглощения падающего на PSC светового потока и уменьшает потери при переносе фотовозбужденных носителей заряда.

Из рис. 3, $b$ видно, что область наиболее эффективной работы CЭ типа DSC находится в интервале 350-700 nm. При этом высокие значения IPCE в PSC-элементах наблюдаются в более длинноволновой области спектра до $800 \mathrm{~nm}$. Таким образом, система DSC/PSC позволяет эффективно утилизировать более широкую область солнечного спектра.

Анализ BAX верхней и нижней ячеек указывает на то, что степень поглощения светового потока в верхней ячейке DSC составляет около $60 \%$. Помимо абсорбции в активном слое фотопреобразователя имеет место также паразитная абсорбция в объеме электролита и слое FTO. Преимуществом предложенной трехэлектродной конструкции ТСЭ с общим противоэлектродом является меньшее количество компонентов системы, чем в классических тандемных схемах [10]. Благодаря этому уменьшаются оптические потери как в объеме ТСЭ, так и на границе раздела верхней и нижней ячеек. Следует также отметить, что DSC-элементы на основе диоксида титана содержат несколько полупрозрачных слоев, варьируя толщины которых, можно контролировать степень оптического пропускания верхнего элемента.

Таким образом, нами были разработаны и изготовлены новые типы ТСЭ с высокими значениями эффективности фотопреобразования, состоящие из комбинаций солнечных элементов DSC и PSC с центральным противоэлектродом: DSC/DSC и DSC/PSC. Результаты анализа

Письма в ЖТФ, 2018, том 44, вып. 3 

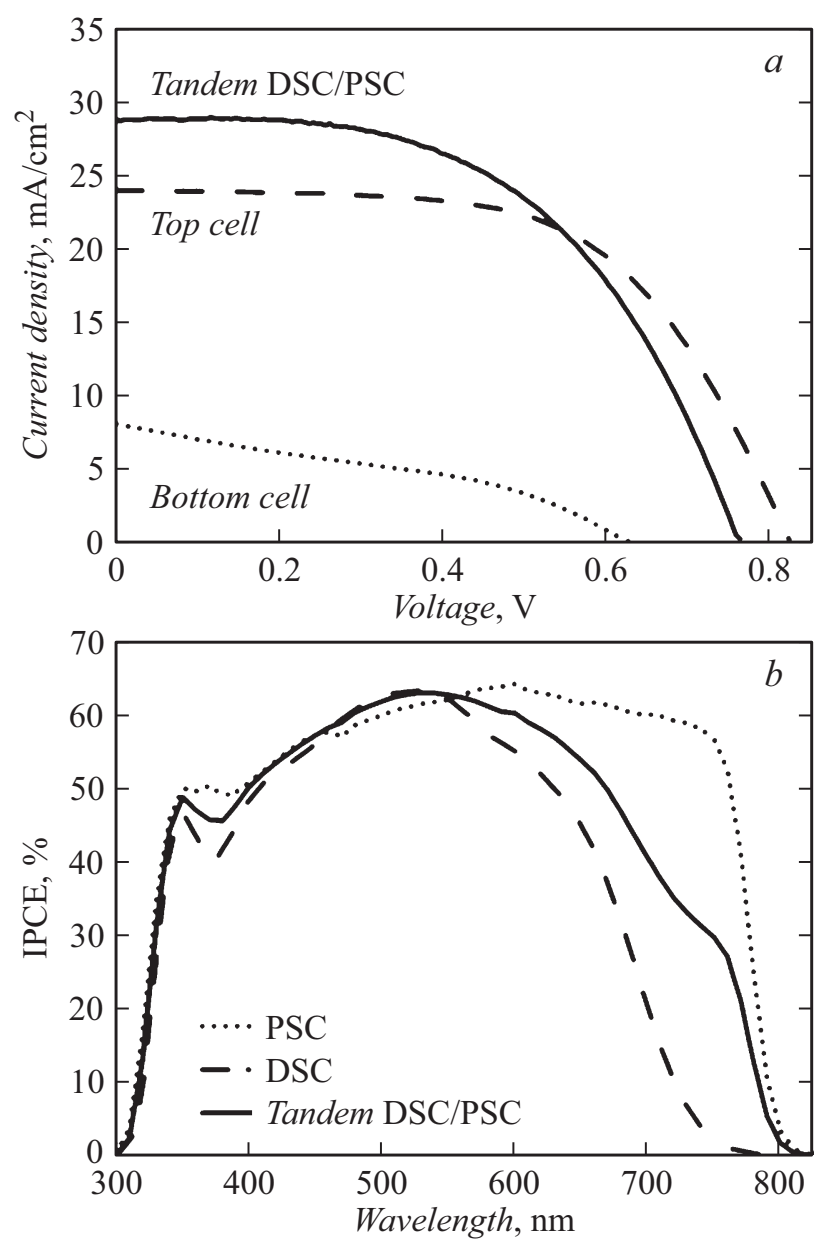

Рис. 3. ВAX ( $a)$ и спектр внешней квантовой эффективности $(b)$ TCЭ DSC/PSC с центральным противоэлектродом.

фотовольтаических характеристик подтверждают эффективность предложенной схемы сочетания DSC- и PSC-элементов в ТCЭ, а также использования трехконтактной схемы с центральным противоэлектродом в сравнении с классическими тандемными системами. Полученные

Письма в ЖТФ, 2018, том 44, вып. 3 
данные свидетельствуют о перспективности использования тандемной схемы DSC/PSC, эффективность которой может быть значительно повышена за счет оптимизации фотоэлектрических параметров PSCэлемента.

Работа выполнена при поддержке гранта РНФ (проект № 17-1901776).

\section{Список литературы}

[1] Law M., Green L.E., Johnson J.C., Saykally R., Yang P. // Nature Mater. 2005. V. 4. N 6. P. 455-459.

[2] Kaltenbrunner M., White M.S., Glowacki E.D., Sekitani T., Someya T., Sariciftci N.S., Bauer S. // Nature Commun. 2012. V. 3. P. 770.

[3] Dao V.D., Larina L.L., Choi H.S. // J. Electrochem. Soc. 2014. V. 161. N 14. P. H896-H902.

[4] O’Regan B., Grätzel M. // Nature. 1991. V. 353. N 6346. P. 737-740.

[5] Mathew S., Yella A., Gao P., Humphry-Baker R., Curchod B.F.E., AshariAstani N., Tavernelli I., Rothlisberger U., Nazeeruddin M.K., Grätzel M. // Nature Chem. 2014. V 6. N 3. P. 242-247.

[6] Sai H., Matsui T., Koida T., Matsubara K., Kondo M., Sugiyama S., Katayama H., Takeuchi Y., Yoshida I. // Appl. Phys. Lett. 2015. V. 106. N 21. P. 213902.

[7] Balasingam S.K, Lee M., Kang M.G., Jun Y. // Chem. Commun. 2013. V. 49. N 15. P. 1471-1487.

[8] Ozawa H., Shimizu R., Arakawa H. // RSC Adv. 2012. V. 2. N 8. P. 3198-3200.

[9] Chevaleevski O., Larina L., Lim K.S. // Proc. 3rd World Conf. on photovoltaic energy conversion. Osaka, Japan, 2003. V. 1. P. 23-26.

[10] Dürr M., Bamedi A., Yasuda A., Nelles G. // Appl. Phys. Lett. 2004. V. 84. N 17. P. 3397-3399.

[11] Kojima A., Teshima K., Shirai Y., Miyasaka T. // J. Am. Chem. Soc. 2009. V. 131. N 17. P. 6050-6051.

[12] Tsvetkov N., Larina L., Shevaleevskiy O., Al-Ammar E.A., Ahn B.T. // Prog. Photovoltaic Res. Appl. 2012. V. 20. N 7. P. 904-911.

[13] Lee M., Teuscher J., Miyasaka T., Murakami T.N., Snaith H.J. // Science. 2012. V. 338. N 6107. P. 643-647.

[14] Ito S., Shen P., Comte P., Nazeeruddin M.K., Liska P., Péchy P., Grätzel M. // Prog. Photovoltaics Res. Appl. 2007. V. 15. N 7. P. 603-612.

[15] Im J.H., Lee C.R., Lee J.W., Park S.W., Park N.G. // Nanoscale. 2011. V. 3. N 10. P. 4088-4093. 